\title{
On the Interpretation of the Results of Water Culture Experiments.
}

\author{
BY
}

\section{WALTER. STILES.}

\section{INTRODUCTION.}

W HEREVER a process is a function of several independent factors, it is necessary to consider the possible influence of all the others when the relation between the rate of the process and any one of the factors is examined. In plant physiology the outstanding example of this is to be found in carbon assimilation. The processes summed up under this term depend upon at least three independent variables: carbon dioxide, temperature, and illumination. As a result of F. F. Blackman's exposition, it was shown that increase in any one of these factors brought about a corresponding increase in assimilation, provided the other factors were present in quantity sufficient for the assimilation to proceed at the increased rate. Thus to choose one factor, temperature, the rate of the assimilation is more than doubled if the temperature is increased $10^{\circ} \mathrm{C}$., but it is self-evident that when the assimilation proceeds at this increased rate more than twice as much carbon dioxide will be used up in any given time than at the lower temperature. Now if in this time the leaf is not supplied with this larger quantity of carbon dioxide, the assimilation obviously cannot proceed at the maximum possible for that temperature. The amount of carbon dioxide under these conditions is a limiting factor.

In water culture experiments there is usually measured the increase of growth, during a certain time, corresponding to some definite composition of the nutrient solution. In other words, experiments with water cultures attempt to determine the effect upon growth of factors acting through the root system. As growth depends upon so many factors, it is very necessary in drawing conclusions from water culture experiments to bear in mind the possible action of factors other than the one under investigation. That the neglect of this is probably the cause of divergent results obtained by different experimenters with the water culture method will be shown in this paper.

\section{The Complexity of The System.}

Growth, in the sense of increase in the total dry matter of a single plant, is the resultant of a large number of inter-related processes, of which

[Annals of Botany, Vol, XXX. No. CXIX. July, I916.] 
the chief may be considered as assimilation and respiration. Any factor which will influence either of these will also influence growth. Assimilation in the wide sense may be dependent upon all those environmental factors that influence carbon assimilation, chief among which are temperature, carbon dioxide, and light. In addition it may be influenced and therefore limited by factors acting in the first place through the root system, water-supply, and supply of nutrient substances in the solution surrounding the roots. The respiration will certainly be influenced by the concentration of oxygen and carbon dioxide in the solution surrounding the roots, and the concentration of these gases in the nutrient solution will thus influence growth.

Besides these obvious factors, others are possible. For instance, the concentration of the nutrient solution might influence growth by affecting the absorption of necessary salts, or by influencing transpiration. It has been shown by the writer ${ }^{1}$ that under certain conditions the concentration of the nutrient solution over a fairly wide range of variation does not act as a limiting factor in growth in water culture. Recently Dr. W. Brenchley ${ }^{2}$ has asserted the contrary, her conclusions being based on several series of experiments in which the growth of plants was apparently dependent on the concentration. It will be shown here that Dr. Brenchley's results are in all probability due to the confusion of two possible factors-the absolute amount of salt available, and the concentration of the solution; and that in her experiments the growth was limited, not by the concentration but by the insufficiency of the total quantity of salt supplied, the initial concentration of the solutions not being maintained throughout her experiments.

\section{The FACTORs.}

In discussing the various factors which may influence the rate of growth of plants in water culture, only those will be considered which act through the root, as it is for the purpose of investigating these that water culture experiments are usually carried out. At the same time it must be recognized that factors acting through the subaerial part of the plant may limit growth, and that generally during the twenty-four hours of any day a series of factors probably limits growth at different times. Only a very approximate parallelism can then be expected between the rate of growth and any particular factor even when this is the chief limiting factor during the day.

I. Supply of 'Nutrient' Salts. As the plant body consists of complex substances which contain various elements only derivable from salts present in the solution surrounding the roots, it is clear that if the

1 Stiles, W. : On the relation between the Concentration of the Nutrient Solution and the Rate of Growth of Plants in Water Culture. Ann. of Bot., vol. xxix, 1915, pp. 89-96.

${ }^{2}$ Brenchley, W. E. : The Effect of the Concentration of the Nutrient Solution on the Growth of Barley and Wheat in Water Cultures. Ann. of Bot., vol. xxx, 1916, pp. 77-90. 
supply of any one of such salts should be below a certain amount, such a salt may act as a limiting factor on growth. When this is the case an increase in salt supply will bring about a corresponding increase in growth. On the other hand, if some other factor is limiting growth, an increase in salt supply will not result in any increase in growth.

If through the limiting action of any factor, as for example temperature, the rate of growth is small, we may therefore expect plants to be unaffected over a wide range by the total amount of nutrient salt supplied. When, however, owing to increase in the value of this factor, a higher rate of growth is possible, we may expect the limiting action of quantity of salts supplied in a given time to be present over an increased range of concentrations.

Results already published appear to show this very clearly. Cultures were grown by the writer, and more recently by Dr. Brenchley, in solutions of the same relative composition but of different concentrations $\left(I, \frac{1}{5}, \frac{1}{10}, \frac{1}{20}\right)$. Considering only those cultures in which the nutrient solutions were frequently renewed, we may take for granted that in the cases where the highest concentration was employed the salt supply was not limiting. ${ }^{1}$

When the rate of growth in the strongest solution is rapid, as in Dr. Brenchley's experiments, although the growth is about the same when the total supply of salts is reduced to $\frac{1}{5}$, yet further reduction in salt supply causes a marked reduction in growth.

In the experiments of the writer the rate of growth in the highest strengths of solution was not so great as in the case of Dr. Brenchley's plants, probably owing to temperature acting as a limiting factor. Here there was no marked reduction in growth until a much lower strength $\left(\frac{1}{20}\right)$ of solution is reached.

Again, in the preliminary experiments of the writer made with Rye during the winter months, when growth was still slower, there was no significant lowering of growth even in the case of plants growing in solutions of $\frac{1}{20}$ the concentration of the strongest.

The following table summarizes the results of both writers:

Grammes $\mathrm{KNO}_{3}$ supplied in highest strength of solution.

$10 \cdot 8$
$10 \cdot 8$
$9 \cdot 0$
$9 \cdot 0$
$7 \cdot 8$

Growth (dry matter in grammes) in solutions of relative strength.

\begin{tabular}{llll}
\multicolumn{1}{c}{ I } & \multicolumn{1}{c}{$\frac{1}{5}$} & \multicolumn{1}{c}{$\frac{1}{10}$} & \multicolumn{1}{c}{$\frac{1}{20}$} \\
0.059 & 0.072 & 0.059 & 0.060 \\
0.628 & 0.622 & 0.555 & $0.47 \mathrm{I}$ \\
4.00 & 3.65 & 2.80 & $\mathrm{I} .83$ \\
5.77 & 4.50 & 2.74 & 1.97 \\
6.46 & 6.04 & 3.09 & 1.78
\end{tabular}

Observer.

Plant.

$\begin{array}{cc}\text { Stiles. } & \text { Rye. } \\ \text { Barley. } \\ \text { Brenchley. } & ", \\ \text { ", } & \text { ", }\end{array}$

1 This is indicated by Dr. Brenchley's observation that 25 per cent. of the original supply of nitrate was still left in such a culture solution that was unchanged for eight weeks. However, in this case there was almost certainly limitation of growth due to other factors, as, for instance, accumulation of carbon dioxide in the culture solution. 
If one considers the last series only, it will be observed that reduction of the supply or nutrient salts to one-fifth of the maximum supplied was accompanied by only a slight diminution in the amount of dry matter produced. With further reduction the diminution is very marked, and the total growth is fairly proportional to the quantity of nitrate supplied. It suggests strongly that the amount of salt supplied in the $\frac{1}{5}$ strength was just a little below the quantity required to allow the other factors present full play. A reduction below this critical quantity means that the salt supply is a limiting factor. Dr. Brenchley's published curves show this point very clearly.

One would not, of course, expect an exact proportionality between salt supplied and quantity of growth, having regard to the complexity of the system and the constant change, not only of other factors but also of the rate of salt supply. For the plants grow larger with time, both their absorptive and assimilatory systems increasing in size; but the quantity of salt supplied in the same time remains the same. The supply per unit of plant is therefore constantly decreasing. It is quite probable that only after the plants have reached a certain size will their demands on the salts be sufficient for the rate of salt supply to become a limiting factor. Thus Dr. Brenchley says, 'The development of the shoots in the plants growing in the different concentrations was very similar for some long time, but gradually a falling off was noticed with the two lowest $\left(\frac{N}{I O}, \frac{N}{20}\right)$, and by harvest time some indications of this appeared even with $\frac{\mathrm{N}}{5}$ shoots'.

Again, Dr. Brenchley writes that her results indicate 'that with the lower strengths the amount of growth was strictly limited by the quantity of food supplied, and that it was impossible for the plants to reach full development with such a restricted amount'. This is exactly the point. The supply of some nutrient salt is acting as a limiting factor. But there is no indication that it is the concentration of the nutrient solution that is limiting. The possibility of this as a factor will be dealt with later.

2. Respiration. There seems to have been a strong tendency with workers on water cultures to avoid considering the undoubtedly important fact that roots respire. In this process roots no doubt absorb oxygen and evolve carbon dioxide, and these processes, one would think, must influence the rate of growth of a plant in water culture.

As regards carbon dioxide, it has long been recognized that the concentration of carbon dioxide in the medium external to plant tissue may influence its activity. In the case of water cultures the carbon dioxide produced by the respiration of the root will dissolve in the culture solution, and unless it reacts with any of the dissolved salts its concentration in the solution will gradually increase until it may act as a factor limiting 
respiration. It is possible that in this accumulation of carbon dioxide in the culture solution is to be found the explanation of the less growth of plants growing in solutions which are not renewed, but which nevertheless contain enough salts for a more rapid growth. The following numbers, taken from a previous paper of the writer's, exhibit this point:

$\begin{array}{clccc}\begin{array}{c}\text { Initial concentration } \\ \text { of food solution. }\end{array} & \begin{array}{c}\text { Solutions } \\ \text { renewed. }\end{array} & \begin{array}{c}\text { Relative total quantity } \\ \text { of salts supplied. }\end{array} & \text { Growth. } & \text { Time of growth. } \\ \mathrm{I} \cdot 0 & \text { Once } & 2 \cdot 0 & 0.3 \mathrm{I} & \text { April 30-June } 9 . \\ 0 \cdot 2 & \text { Eight times } & 1 \cdot 8 & 0.62 & \text { April 28-June 6. } \\ 0.05 & \text { Eight times } & 0.45 & 0.47 & \text { April 28-June 6. }\end{array}$

A diminution of the oxygen dissolved in the culture solution might also affect growth and act as a limiting factor. In the absence of any data it is impossible to say how far this factor may be operative. The partial pressure of each gas in the culture solution will always be tending to come into equilibrium with the partial pressure of the same gas in the atmosphere, but there is no doubt a constant lag in the bringing about of this equilibrium.

3. Concentration of the Nutrient Solution. The extent to which concentration of the nutrient solution can act as a limiting factor is difficult to examine, because from the moment the plant roots are put in the solution the concentration will be altering. It was in an attempt to minimize this difficulty that the writer changed the water culture solutions at frequent intervals. Even then the concentration of the nutrient solution will only remain very approximately constant when the rate of growth is slow. This was the case with the writer's experiments, in which it was shown that the variation in the concentration of the nutrient solution over a fairly wide range has little influence on the dry matter produced. In the lowest strengths of solution employed there was a slightly less rate of growth, but this might have been due to the insufficiency of one of the nutritive salts during the later days of growth.

Dr. Brenchley states in her recent paper that when plants 'are grown in water cultures under favourable conditions, the concentration of the nutrient solution, up to a comparatively high strength, has a great effect upon the rate of growth'. As a matter of fact her experiments do not support this statement. Indeed her results properly examined rather indicate the reverse. In the following table, compiled from Dr. Brenchley's results, it is shown how much better growth results in solutions of low concentration when these are frequently changed, than when they are not. The improvement in the case of higher concentrations is relatively much less. In order to show this clearly the weight of the plant in the neverchanged solution is taken as unity in the case of each concentration in each series, and the weights of the corresponding plant in the once changed and frequently changed solutions are given relatively to this. 
Series I.

Never changed

Once changed .

Frequently changed .

Series 2.

Never changed

Once changed . . . . . $\quad \mathbf{I} \cdot 188$

Frequently changed . . . $\quad 1 \cdot 35^{2}$

Series 3.

Never changed . . . $1 \cdot 000$

Once changed . . . .

Frequently changed . . .

\section{Relative concentration of solution.}

$\begin{array}{cccc}I & \frac{1}{5} & \frac{1}{10} & \frac{1}{2} 0 \\ \mathrm{I} \cdot 000 & \mathrm{I} \cdot 000 & \mathrm{I} \cdot 000 & \mathrm{I} \cdot 000 \\ \mathrm{I} \cdot 274 & \mathrm{I} \cdot 443 & \mathrm{I} \cdot 493 & \mathrm{I} \cdot 628 \\ \mathrm{I} \cdot 520 & 2 \cdot 600 & 3 \cdot 386 & 4 \cdot 05 \mathrm{I} \\ & & & \\ \mathrm{I} \cdot 000 & \mathrm{I} \cdot 000 & \mathrm{I} \cdot 000 & \mathrm{I} \cdot 000 \\ \mathrm{I} \cdot \mathrm{I} 88 & \mathrm{I} \cdot 3 \mathrm{I} 9 & \mathrm{I} \cdot 404 & \mathrm{I} \cdot 33^{2} \\ \mathrm{I} \cdot 35^{2} & 2 \cdot 548 & 2 \cdot 936 & 3 \cdot 747 \\ & & & \\ \mathrm{I} \cdot 000 & \mathrm{I} \cdot 000 & \mathrm{I} \cdot 000 & \mathrm{I} \cdot 000 \\ \mathrm{I} \cdot 250 & \mathrm{I} \cdot 64 \mathrm{I} & \mathrm{I} \cdot 25 \mathrm{I} & \mathrm{I} \cdot 759 \\ \mathrm{I} \cdot \mathrm{IO} 2 & 3.74^{8} & 5 \cdot 970 & \mathrm{I} 0.73\end{array}$

It will be observed that whereas the growth of culture in the strongest solutions was only improved from $I \cdot 4$ to $2 \cdot \mathrm{I}$ times by frequently changing the solutions, in the most dilute solutions frequent renewal of the culture medium brought about from 4 to nearly I t times as much growth. It strongly suggests that if the solutions had been changed still more frequently the rate of growth would have been still higher. The results indicate clearly that no conclusions whatever can be drawn from such observations as to the effect of varying concentration of the solution. They indicate that in the lowest strengths the salt supply was deficient and required very frequent renewals. In other words, the actual concentration soon fell below that of the initial concentration after renewal of the solution.

Again, Dr. Brenchley states that for a considerable time all her plants grew as far as the eye could judge at equal rates, but that after that time those in the diluter solutions grew less rapidly than the others. This suggests that in this later period of growth the plants are so large that the nutrient salts supplied in one lot of diluter solution are no longer sufficient for the growth that other factors would allow. The rate of growth is limited, not because of the concentration of the solution, but because the salt supply is not kept up constantly.

The difference between the rate of salt supply and the concentration of the solution supplied at definite intervals may be made clear by considering an extreme case. If an adult oak-tree were grown in a litre of a dilute nutrient solution, supposing such a thing to be possible, it is quite clear that it would not require many minutes for the exhaustion of the food supply. If the solution were renewed every four days, salt supply would still limit growth exceedingly. But if it were supplied with a litre of the same nutrient solution for every square millimetre of absorbing surface, it would take a much longer time for the food supply to be exhausted, and if the solution were renewed every four days it is conceivable that the salt supply would not limit the growth. It is obvious that in the first case it would be erroneous to ascribe limitation of growth to the concentration of the external solution. Yet this is in effect what Dr. Brenchley does.

It is clear from the writer's experiments, and it is indicated also by the 
statement of Dr. Brenchley mentioned above (p. 430), that when plants are growing slowly the concentration of the nutrient solution is without influence on the rate of growth over a wide range. As the plant grows larger it will grow more rapidly because both the assimilative and absorptive systems are larger. If these two systems increase at the same rate, it should follow that if concentration of the solution is without influence on the rate of growth when the plant is small, so it should also be without influence on it when the plant is large, for although the plant will require more salts, the absorbing system will be larger and so can obtain more.

The whole question therefore resolves itself into the problem of the relationship between the rate of absorption and the concentration of the medium. It is quite conceivable that below a certain point concentration of the nutrient solution might be so low that the root could not absorb enough salts from the solution simply because of the dilution of the latter. No very definite evidence has, however, yet been obtained of this, although the researches of True and Bartlett ${ }^{1}$ are suggestive in this regard. They indicate that this limiting concentration is very low.

4. Toxic Action of Substances in the Nutrient Solution. The presence of certain substances in the nutrient medium may act as a factor limiting growth. This has been shown to be the case with salts of a number of metals such as copper, zinc, and manganese. An account of such toxic action may be found in Dr. Brenchley's monograph on Inorganic Plant Poisons and Stimulants. The limiting action of such substances is no doubt due to their reaction with substances of the plant which disturb the normal reactions which make up the life processes.

5. The Ratio between the Concentration of different Substances in the Nutrient Solution. Numerous writers have urged as a result of water culture experiments the need for a definite ratio between the constituents of the culture solution for the production of optimum growth. Any wide departure from this ratio causes depression of growth, owing to one of the constituents, being present in excess, entering the plant too rapidly and producing a toxic action. The whole question has been summed up under the name of Antagonism, a general account of which is given in a paper by $\mathrm{Mr}$. Jørgensen and the writer. ${ }^{2}$

There may be something in the idea of balanced solutions, but the evidence in favour of it will not bear analysis. All the experiments adduced in support of it are open to one or two fatal criticisms, and most of them to both. These are:

1 True, R. H., and Bartlett, H. H. : The Exchange of Ions between the Roots of Lupinus albus and Culture Solutions containing one Nutrient Salt. Amer. Journ. Bot., vol. ii, I9I5, pp. 255-78. The Exchange of Ions between the Roots of Lupinus albus and Culture Solutions containing two Nutrient Salts. Ibid., pp. 3 II-23.

${ }^{2}$ Stiles, W., and Jørgensen, I. : The Antagonism between Ions in the Absorption of Salts by Plants. New Phyt., vol. xiii, I9I 4, pp. 253-68. 
(I) No account is taken of the great variation between individual plants growing in water cultures under the same conditions.

(2) In no case has a constantly renewed culture solution been employed. Thus the ratio of the various constituents was probably constantly changing throughout the experiments, and instead of being a constant factor was an unknown and varying one.

Hence the possibility of a lack of balance acting as a limiting factor can be admitted, but it cannot be claimed that such a limitation has been proved in any one case.

In the foregoing pages some of the factors which may limit the rate of growth of plants in water cultures have been dealt with, particularly those which act through the root system, as it is with these that water culture experiments, by their very nature, usually deal. In discussing these questions frequent recourse has been had to Dr. Brenchley's researches, and these have been exposed to some criticism, not because of all water culture experiments they are those which most call for criticism, but because they are those that require it least. They are, for instance, apart from the much fewer ones made by the writer, the only ones in which the limits of error and significance of differences are indicated, and in which therefore recorded differences have a true value. They have also been carried out on a generously conceived plan and under ideal conditions. Much information is to be derived from them as to limiting factors in water culture experiments. But owing in one instance to the confusion of two possible factors the conclusions as regards the limiting action of concentration do not hold.

In endeavouring to explain the difference between her results and the writer's, Dr. Brenchley ascribes the failure of concentration of the nutrient solution to influence growth in the writer's experiment to some other limiting factor (e. g. smoke pollution) which was ignored. Of course the whole point of the experiments was to show that it was some factor other than concentration which limited growth. The factor was probably largely temperature or perhaps illumination. It may have been atmospheric impurity as such, though this is not very likely, and it was certainly not any such factor as copper in the distilled water (which was ' conductivity' water from a block tin still), 'lack of cleanliness in working, growth of algae in culture bottles, admittance of light to the roots'. It would indeed be reprehensible negligence for a scientific worker to allow such factors as these to be operative.

It should also be pointed out that in dealing with such a complex as growth, it is extremely difficult to examine the action of any particular factor upon it. During the twenty-four hours a dozen different factors may limit growth at different times. Nevertheless it is possible and no doubt 
often the case, where one factor is predominatingly the limiting one, to show this is so, and it is also possible to show that a factor is not the limiting one when alterations in its magnitude have no effect on growth.

\section{The Limitations of the Water Culture Method.}

It must be acknowledged at once that experiments with water cultures have in the past yielded information of first importance. Thus it was by their use that the elements necessary for plant growth were demonstrated. More recently in Dr. Brenchley's hands they have given much information as to the toxic properties of various substances. But it is necessary to bear in mind the limitations of the method. In the form in which it has hitherto been employed, the essential of the water culture method is to control the amount of substance added to the nutrient solution and to measure the growth corresponding to this. But growth is the result of such a complex of factors, scarcely any of which are completely under control and many of them not at all. An understanding of the physiology of the plant can only be brought about by careful analysis of factors carefully controlled, and by accurate quantitative measurement.

Again, owing to the variability of individual plants, the method leaves much to be desired as regards accuracy, unless large numbers of plants are dealt with and the probable error of experiment calculated. This makes the method very laborious.

Dr. Brenchley's last published results are probably as accurate as can be obtained by the method, and she has very properly calculated the probable error. The mean of each set of ten plants growing under the same conditions had a probable error range which was often about 4 per cent. of the mean value, rarely below that, and which was frequently as much as 9, IO, or even II per cent. of the mean. Hence for a difference between two mean values to have a reasonably certain significance in these experiments it would be necessary for the means to differ by about Io per cent. to I 5 per cent. in favourable cases, and by as much as 30 per cent. or even more in unfavourable ones. ${ }^{1}$ This cannot be regarded as very satisfactory in comparison with the decree of accuracy which can be obtained by other physiological methods which at the same time are much less laborious. Nevertheless for the solving of some problems the method may be the only one available.

\section{SUMMARY.}

I. Growth, the resultant of a number of different processes, is dependent ultimately upon many separate factors, each one of which may limit the rate of growth.

1 See, for example, Gray, F, W.: A Manual of Practical Physical Chemistry, London, I914, chapter i. 
2. Water culture experiments are usually performed in order to examine the influence of certain factors upon growth, by controlling the action of these factors acting through the root.

3. Owing to the neglect of the possible effect of other factors, and to the difficulty of controlling most of these factors in water cultures for any length of time, it may be difficult to obtain definite evidence of the relation between any one factor and the rate of growth.

4. It should be obvious as an elementary physiological principle, and it is amply borne out by the results of published experiments, that the supply of nutrient elements in the water culture solution can act as a limiting factor.

5. With this factor has been confused that of the concentration of the nutrient solution. No evidence has yet been obtained that concentration of the nutrient solution acts as a limiting factor, but it is probable that it may so act in exceedingly dilute solutions, and it probably does in very high ones.

6. The possibility of the influence of respiratory activity of the root on the culture solution has been neglected hitherto. This may play a part in limiting growth.

7. The water culture method is of very limited application to physiological problems on account of (I) the difficulty in analysing results due to the complex of factors not under control ; (2) the difficulty of controlling in some cases even the factor whose action is being investigated; and (3) the excess of labour required to produce results which are only of a low degree of accuracy.

LoNDON,

June, 1916. 


\section{$2 \mathrm{BHL}$ Biodiversity Heritage Library}

Stiles, Walter. 1916. "On the interpretation of the results of water culture experiments." Annals of botany 30, 427-436.

https://doi.org/10.1093/oxfordjournals.aob.a089613.

View This Item Online: https://www.biodiversitylibrary.org/item/237452

DOI: https://doi.org/10.1093/oxfordjournals.aob.a089613

Permalink: https://www.biodiversitylibrary.org/partpdf/320130

\section{Holding Institution}

Smithsonian Libraries

\section{Sponsored by}

Biodiversity Heritage Library

\section{Copyright \& Reuse}

Copyright Status: Not in copyright. The BHL knows of no copyright restrictions on this item.

This document was created from content at the Biodiversity Heritage Library, the world's largest open access digital library for biodiversity literature and archives. Visit BHL at https://www.biodiversitylibrary.org. 